\title{
Resectable Liposarcoma
}

National Cancer Institute

\section{Source}

National Cancer Institute. Resectable Liposarcoma. NCI Thesaurus. Code C150606.

Liposarcoma that is amenable to surgical resection. 